\title{
A Review of Traffic Congestion Problem and Various Automated Traffic Measurement Sensors and Techniques
}

\author{
Shilpa Thakur and Ramandeep Singh \\ School of Computer Science, Lovely Professional University, Phagwara - 144411, Punjab, India; \\ tshilpa29@gmail.com
}

\begin{abstract}
Traffic congestion has been a worldwide issue which results into wastage of time, energy and causes environmental pollution. Identification of congestion is the initial step for selecting appropriate method to avoid this situation. To understand congestion in simple way it is classified into different categories. There are number of reasons for the congestion problem. There are numerous potential congestion administration procedures. The suggested two related measures are for traffic management are; Regularity measures and Economic measures. Regularity measures are access management and parking management and pricing policies are economic measures. Economic measures are considered as basic interest side administration measures which can change human practices to maintain a strategic distance from congestion. There are now distinctive sorts of strategies and computerized sensor frameworks exists to examine traffic density and to tackle congestion issue depending on the traffic nature. This paper introduces an outline and possible ways for the identification of traffic congestion problem. The review covers various aspects like definition, congestion categories, characterization and traffic congestion management. This paper reviews different sensor frameworks by encircling the advantages and disadvantages of each in terms of cost, reliability, accuracy, efficiency and maintenance overhead.
\end{abstract}

Keywords: Congestion Categories; Congestion Management; Data Collection Techniques, Traffic Congestion

\section{Introduction}

Traffic congestion is a major challenge for our day to day life. Traffic blockage is a condition where the traveling rate is below the free stream speed out on road and highway ${ }^{1}$ which is aftereffect of expanded traffic volume. When vehicles are fully stopped for a particular period of time, traffic congestion situation arises. This can be solved by implementing a well-planned process that handles the congestion in smart manner. The first step to solve congestion problem is to understand the basic reasons for congestion in various congestion tackling phases. It can also be done by developing the relevant congestion indicators for monitoring and utilizing the existing and creating additional capacity using new technology and infrastructure.

\subsection{Congestion Classification}

To understand traffic congestion in a complete manner, it can be further classified into following categories:

- Facilities: The distinctive sorts of roads where the congestion happens, for example, highways, streets, bridges etc.

${ }^{*}$ Author for correspondence 
- Magnitude: The force, course of events, degree and variability of congestion.

- Recurring vs. Non-recurring:

- In the event that congestion happens for ordinarily at the same area for the specific extent, it is known as recurring congestion\|, else it is categorized as non-recurring congestion. For example, congestion intensity can vary according to holidays and festivals and also due to peak working hours. According to the given report ${ }^{1}$

$\checkmark$ The congested condition rehashes once per day for a month because of some climate conditions and the delay range was between 10 to 20 minutes for every vehicle.

D Congestion rehashes least for 20 days in a month for road upkeep (work in advancement zone) where speed decrease separates 15 to 20 percent

- Systemic definition for effect or region of influence: Congestion must be named "limited" if the length of its impact, power and course of events is not more than certain edge which is controlled by the organizations, else it would be considered as systemic congestion. There are couple of case for the systemic congestion edges, in view of a given report ${ }^{1}$ :

- The delay time of a congested condition's is not over 15 minutes for a vehicle.

- The delays for aggregate vehicle are not more than 1,000 vehicle hours.

- The course of events for a congested condition is under 30 minutes.

\subsection{Various Reasons for Traffic Congestion}

\subsubsection{Increase in Population}

More cars on the roads are one of the reason which leads to increase in congestion. As the financial growth of citizen's increase with increase in population, the demand for personal vehicles for daily commute also rises among citizens. Hence the increase in number of vehicles and increase in chances of congestion are directly related.

\subsubsection{Poor Infrastructure}

This is combined with an absence of appropriate framework. The roads don't grow alongside expanding vehicle populace. A solitary road with a lane on every side before might not adequate in ten years after the population has expanded. Powers frequently neglect to change over this into a double carriage way.

\subsubsection{Alternate Route}

Alternate routes are likewise an explanation behind this issue. Roads have constrained ability to extend because of low spending plan and lack of poor planning limitations. Roads are compelled to work with the courses they as of now have. So the less number of lanes additionally prompts congestion.

\subsubsection{Flexible Working Hours}

Congestion quite often happens when individuals are travelling out to and from work. Traffic congestion has facilitated as an after effect of growing unemployment and the presentation of more adaptable work hours.

\subsubsection{Lack of Public Transport}

The absence of public transport or poor public transport additionally causes congestion issue. On the off chance that there are insufficient transports, trams,individuals are compelled to take their own vehicles to work.

\subsubsection{Bottleneck}

Traffic bottleneck is limited disturbance of vehicular movement for an interval of time on a road, street or highway as shown in Figure 1.

Traffic bottleneck problems are categorized on the basis of different situations. The main categories of bottleneck are:

\section{Static bottleneck:}

Problems like poor road alignment, narrowing of road width, on-ramps, off-ramps, and entrance of tunnel are some of the fixed static bottlenecks which are most familiar. 


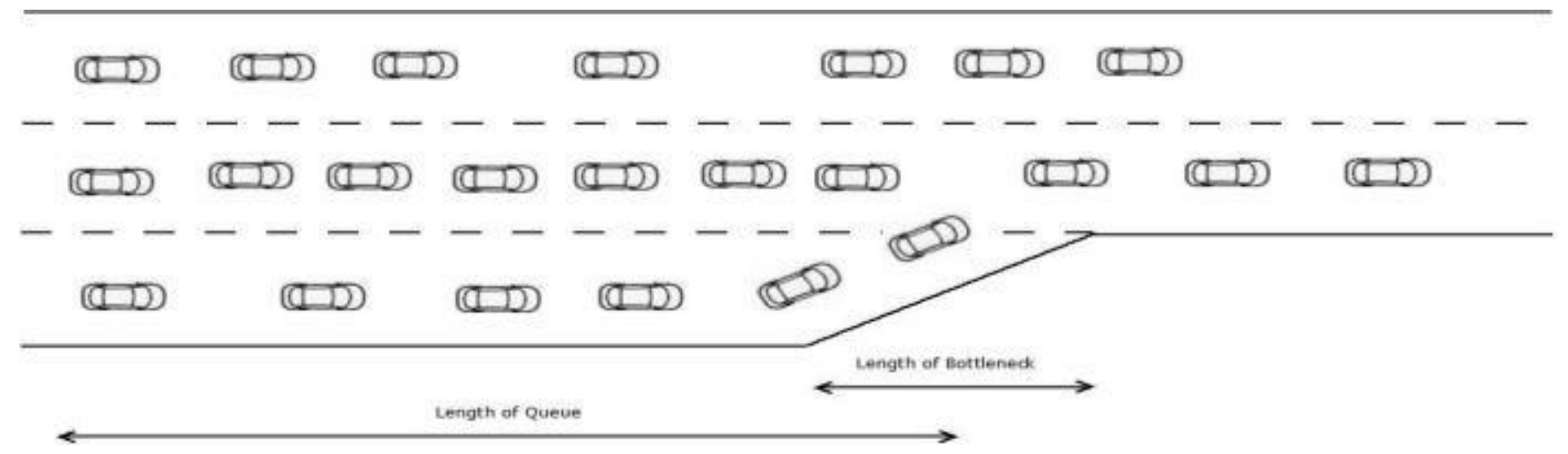

Figure 1. Traffic congestion due to bottleneck situation.

\section{Dynamic bottleneck:}

The distribution in continuous flow in general traffic because of slow moving vehicles id defined as dynamic bottlenecks problem in highway traffic. For example, heavy equipment pulled by a truck or a long convey or oversized vehicles. According to the different reports of research $\stackrel{1,2}{ }$ traffic bottleneck problem is the main reason for the situation of traffic congestion. So, to avoid this situation we have to start with understanding bottleneck situation and its different causes.

\section{Road Transportation Bottlenecks causes:}

The major hurdles in the free flow of traffic are Bottlenecks. This problem occurs mostly when nearing capacity. In a given survey ${ }^{3}$ there are four major causes which lead to traffic bottleneck and it can be identified as:

\section{Traffic interruption:}

Most common causes of traffic interruption include railway crossing, traffic lights, tolls and stop signs. As there is no legitimate synchronization of traffic lights with the stream of flow of traffic, the odds of critical delays can emerge while the traffic accumulates in one direction. Tolls can likewise prompt bottleneck, for the most part in urban territories, as more often than not can be spends in the installment of manually gathered fare.

\section{Lane reduction:}

With the number of reduction in lanes the probability of bottleneck easily increases. Especially it happens when the capacity on the current segment becomes less comparing to the previous segment.

\section{Merging:}

To provide an easy flow to traffic highways are designed, as road transports slows down while changing the lanes, the merging becomes the cause for bottlenecks. This is the situation where the convergence of two highways happens and expansive measure of the traffic shifts starting with one highway then onto the next highway.

\section{Distraction:}

Distraction is a kind of bottleneck which is made by mental response of the drivers to any strange occasion. It doesn't straightforwardly influence the limit; it occupies and causes a stoppage in traffic. Distractions can likewise be an outcome of a car that has been pulled over by the police. Glare during the dawns and nightfall's additionally make bottlenecks over highway sections. 

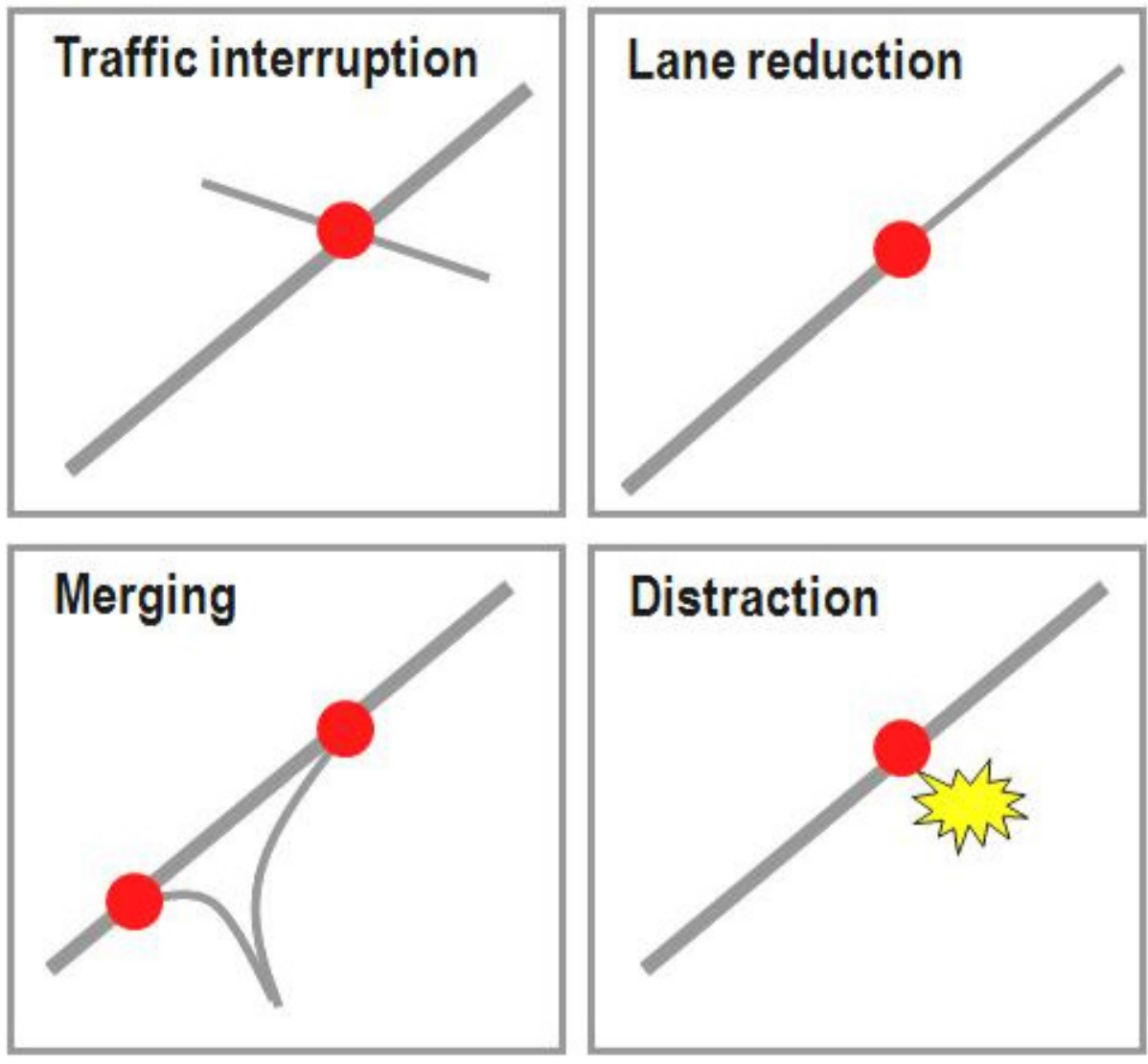

Figure 2. ${ }^{3}$ Traffic bottleneck reasons.

\section{Traffic Congestion Management}

4There are numerous potential congestion administration procedures however most can be categorized as one of two classes - those that give new limit or free up existing limit and those that top limit or generally oversee traffic levels on the new or authorized limit. ${ }^{5}$ suggested two related measures;

Regularity measures and Economic measures. Regularity measures are access management and parking management and pricing policies are economic measures. 5Likewise gather to guarantee that area use arranging, and the group targets it incorporates, is composed with congestion management strategies. In this way, European Conference of Ministers of Transport (ECMT) really depicts three periods of interest side clog administration; regulatory, money related and arrive use. These three phases are also depicted by ${ }^{6}$ as successful interest side clogs relief measures.

\subsection{Regulatory measures}

Administrative measures fundamentally allude to regulatory measures, strategies or controls that specifically change the explorers 'practices ${ }^{6}$. Administrative measures incorporate; access administration, stopping control, confinements on vehicle use, activity calming and versatile working hours. It has numerous imperatives. Firstly, to the general population, these measures incorporate restriction on vehicle use and these are excessively strict, making it impossible to human self-sufficiency. In this way, these can't be functional to each country. 
Furthermore, these measures always seriously influence financial well-creatures by changing normal traffic flows.

\subsubsection{Access Management}

The access arrangement restrains the vehicle access to a few districts for instance recorded focuses or to the specific street joins like ramp metering. In the circumstance of district based limitations, the traffic is block by utilizing the physical barriers as a part of the urban ranges road system (for e.g. the roads systems and one-way avenues are organized in such a way, to the point that it prevents the traffic) $)^{4}$ or through permit based systems or by traffic bans. To ensure that a delicate single measure should not responsible for handling all main of traffic reduction efforts, the restriction regions should be linked with the set of measures which are supplementary to each other. Some supplementary restrictions can result in quality public transport, pricing and parking controls. The reduction in capacity leads to prevent access to those regions.

\subsubsection{Parking management}

Parking management will be steady in little perspectives in the conditions where there is demand for drop off or get travelers, similar to guardians taking their youngsters from school. Due to availability of operational flexibility and significant policy, parking control can also be implemented on the time and location basis. To ensure a desired result other measures like pricing or access control can be used for parking management. However, if parking prices is increased within the policies of parking control then profit will also get increased for further congestion reduction.

\subsection{Economic Measures}

Economic measures are considered as basic interest side administration measures which can change human practices to maintain a strategic distance from congestion. Different economic measures are found through literature survey, for example, tax assessment, sponsorships, mixed use instrument streets, cordon charges, street tolls, blockage assessing/Tax, range approving arrangement, electronic street evaluating, cordon charges, associated based pricing framework and so forth.

\subsubsection{Pricing Policies}

Street evaluating or blockage assessing is a fundamental monetary measure for diminishing clog. The expense on street framework charged on all drivers and it can specifically diminish driver's energy to utilize roads. It encases road tolls and congestion evaluating ${ }^{6}$. Favorable position to blockage valuing is that the charges and earnings can help offering advantages for undertaking need transport ventures (e.g. in broad daylight transport, ITS establishment or street development) ${ }^{5}$. Public is not concurring with tax assessment and congestion evaluating in light of the fact that it is seen as an extra duty and nobody needs to be pay for something that was free some time recently. Rather than confronting such issues, numerous urban communities respect clog valuing as a last option since it is suitable for diminishment in blockage issues ${ }^{6}$.

\subsection{Land use Policies}

Experience from various nations and districts have demonstrated that, area use arrangements are essential for altering the activity stream lopsidedness to address clog issue over the long haul. Land utilizes rises trip era and expansions local outing designs. In this way, arrive utilizations ought to be re-situated in such a way, to the point that the need and the sum to travel can be minimized. With ideal area use and advancement approaches, the interest for travel can be decreased to the slightest level ${ }^{6}$.

\section{Traffic Measurement Techniques: Survey}

Traffic responsive control framework for the most part relies on its capacity which sense movement for neighborhood convergence control furthermore for framework wide change of arranged planning. Framework fulfills this by utilizing the one or more from the accompanying sorts of detector. These detectors are further classified into two categories. This classification is generally depending on their nature of installation. The devices which needs pavement cut for installation are inductive loop, magnetometer, magnetic sensors and devices which don't need any pavement cut for installation are microwave radar, infrared sensor, ultrasonic, video image processing. 


\subsection{Pavement Invasive Detectors}

\subsubsection{Inductive Loop}

The nearness of conductive metallic article is detected by an inductive-loop through influencing streams in thing, this minimize the circle inductance. Inductive circle are classified in four segments, namely, wire circle of many turns are fixed in the expressway black-top, starting from running of wire through wires circle and draw box, interfacing the opener wires in electrical box to control unit, lastly equipment unit grouped into controller authority which can be seen in Figure 3. Inductive-circle senses the proximity of a conductive metal by instigating electrical streams. Incited current decreases the circle inductance. The devices unit disentangles the reduced inductance as transport acknowledgment and passes a reasonable signal to control unit.

Figure 3 demonstrates inductive-circle pointer structure containing the turns of wire put around the expressway that is related by lead wire in an electrical system arranged along the edge of the roadway. The electrical system subsequently is attached through lead-in to an equipment entity in authority. Equipment enables the circle of wire, separating the sign and transmitting object disclosure details to the control unit.

\subsubsection{Magnetometer}

Measures are alert in the flat and additionally in the vertical segments of earth's attractive field. Prior magnetometers just used to recognize the vertical segment, and not ready to work close equator, as there the attractive field line are even. In any case, now two-pivot fluxgate magnetometer has acquainted with conquer this issue. Magnetometers are likewise valuable on the scaffold decks or viaducts, where there is meddles of steel bolster structure with circle locators, and the circles debilitate the present structure. These are additionally useful for transitory establishments in development zones.

\subsubsection{Magnetic}

These types of sensors are inactive prototypes which perceive the closeness of strong substance like metal from the alluring exception, caused by them in the Earth's magnetic area ${ }^{9}$ Figure 4 presents the view of magnetic anomaly generated by magnetic dipoles. Upper bit of Figure 4 demonstrates the generation of magnetic anomaly by direction extension of dipole appealing area to the quiet magnetic area of earth. Downward portion of figure indicates the combine dipoles on an object and effect of dipoles on compass interpretation and detector output.

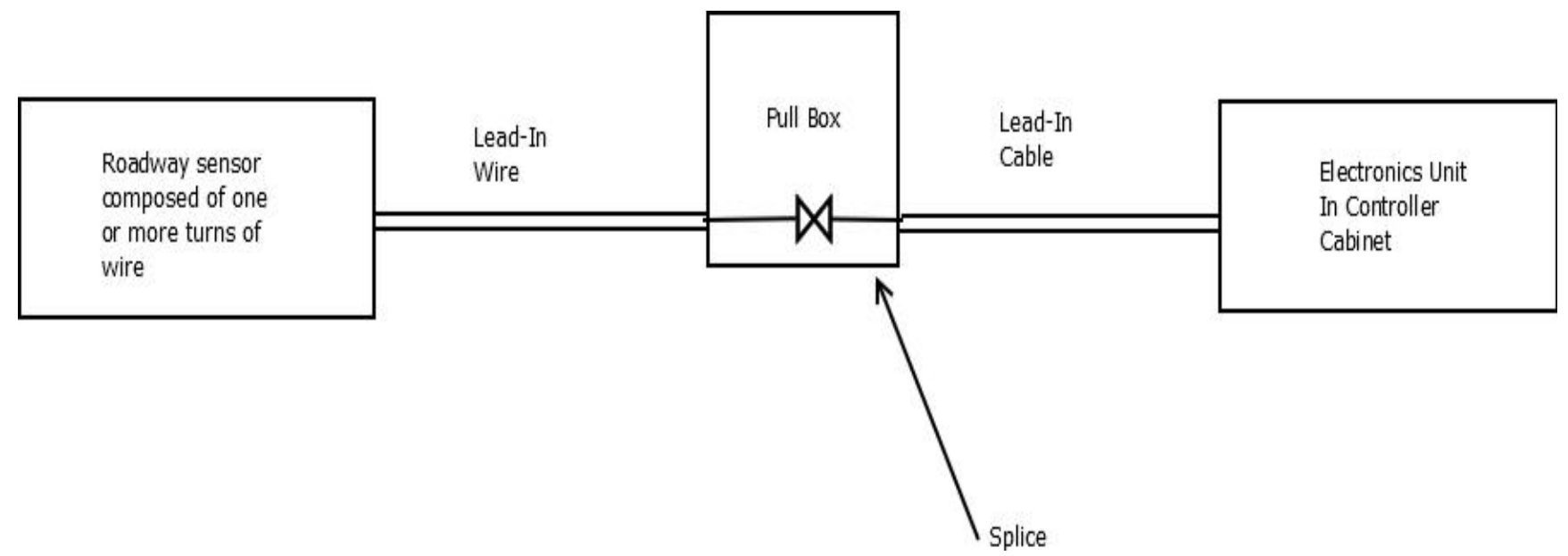

Figure 3. Inductive-Loop sensor method. 


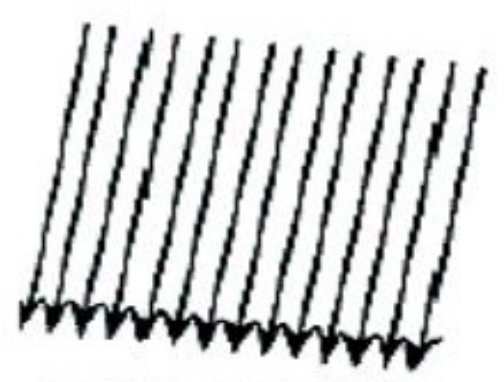

Earth's magnetic neld r absence or metal venicle

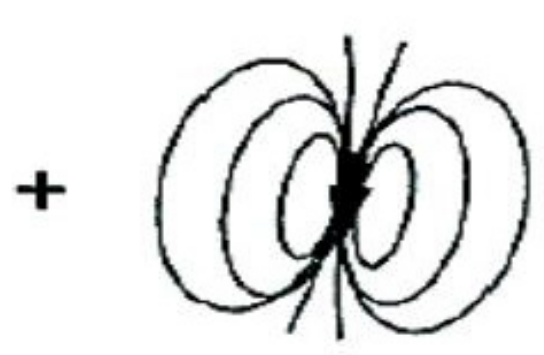

Magnetic dipole produced by rerrous materials

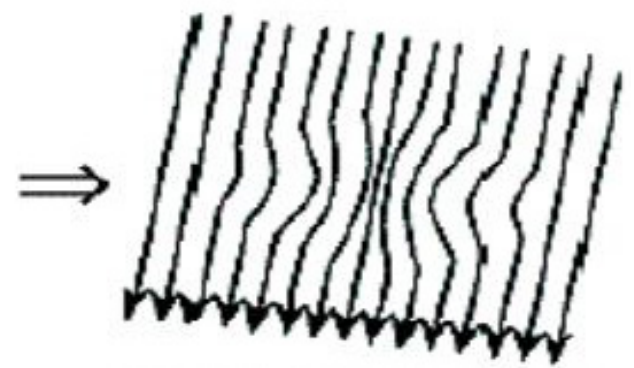

Resultant magnetic anomaly in Earth's magnetic neld

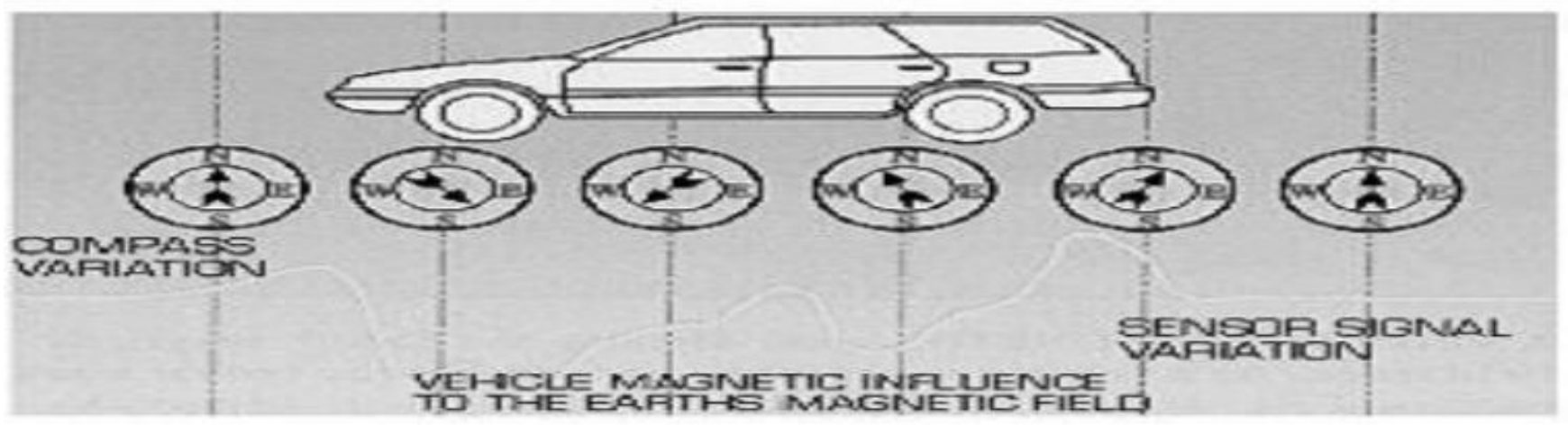

Figure 4. Sensing by using magnetic principles.

For traffic flow parameter estimation there are generally two sorts of magnetic field sensors are used. The starting class, the two-axis magnetometer, locates variations in magnetic area of earth produced by ferrous object of metal. In result of the appealing field irregularity, which means the alluring feature of an object, the magnetometer's hardware calculate yield voltage created by auxiliary bending.

Second kind of magnetic field sensor is the attractive locator; it identifies the object mark by computing contortion in attractive instable lines actuated by adjustment in the Earth's attractive area delivered through a moving metal object.

Magnetic indicators are embedded evenly underneath the roadway. Since they give just section information and not inhabitance or nearness information, their utilization is constrained to extraordinary applications.

\subsection{Non-Pavement Invasive Detectors}

\subsubsection{Microwave Radar}

Radar detector system is used for generating electromagnetic signals and to collect resonances from vehicles of enthusiasm inside its size of scope." Radar was at first an abbreviation for Radio Discovery and Alternating.

Figure 5 shows the broadcast of vitality by overheadmounted microwave radar in the direction of a region of highway. The bar width or territory where the radar vitality is organized by the size and the dispersion of vitality over the opening of the receiving wire. The radar maker ordinarily builds up these configuration requirements. At the point when a car goes over the receiving wire bar, a segment of the conducted vitality is replicated back in the direction of the radio wire. The vitality now passes in a beneficiary where the location is finished and move- 


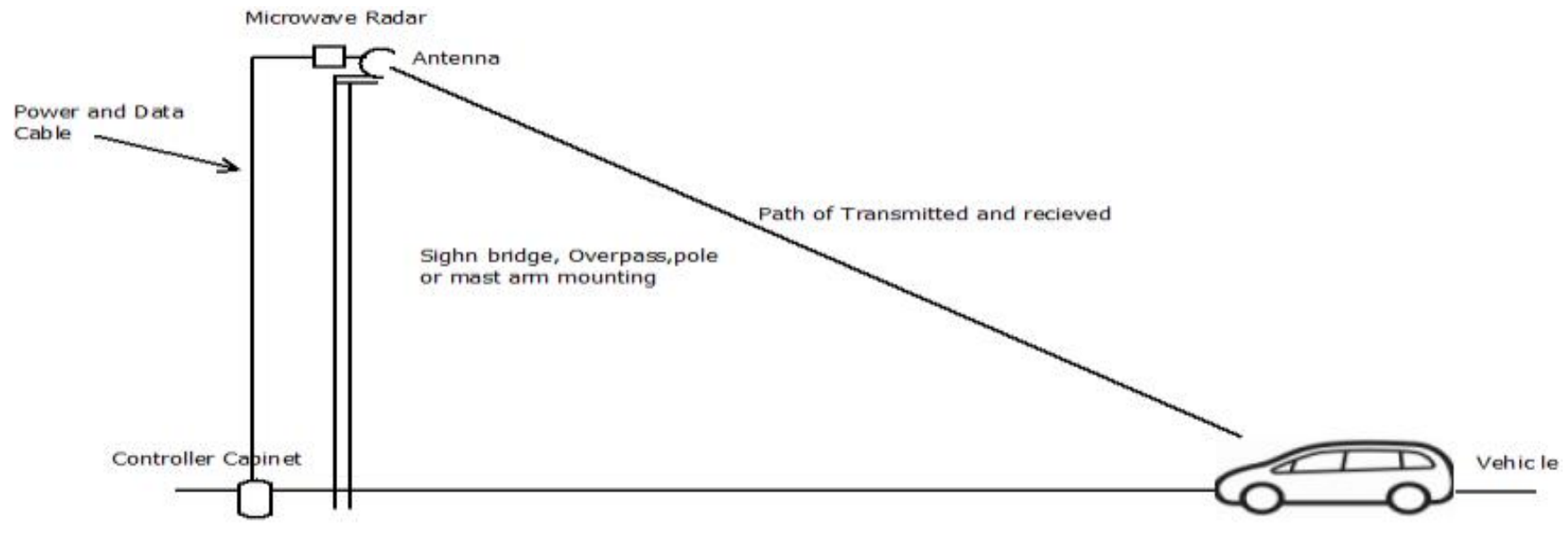

Figure 5. Traffic measurement using microwave radar.

ment stream information, for example, volume, rate, and vehicle length, are computed.

Radar might be fixed above the center of path to gauge drawing closer or withdrawing movement stream factors in a solitary path, along the edge of a highway for quantifying the activity parameters over a few paths as appeared in Figure 6. Forward-looking wide shaft width radars assemble information illustrative of movement stream for bearing over different paths. Forward-looking tight shaft width radars screen a solitary path of activity streaming in one heading. Side-mounted, numerous identification area detectors extend their location region (i.e., impression) opposite to the movement stream heading. Side-mounted radars are used for identifying vehicle nearness in one or more paths at signalized convergences.

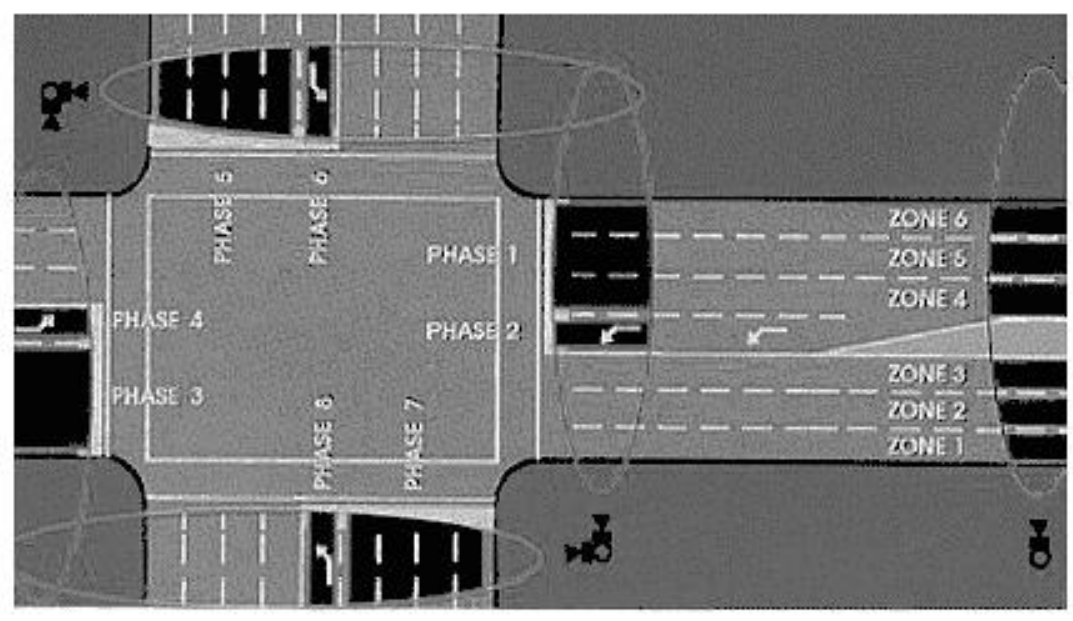

Figure 6. Mounting of microwave radar sensors for multilane vehicle finding and signal actuation at an intersection. 


\subsubsection{Infrared}

Powerful and segregated infrared sensors are created for development stream checking applications. The sign direction kept impediment from various wellsprings of infrared imperativeness, containing daylight. Two transmitter-authority methods measured the automobile rate and evaluated the automobile stature. Standoffish sensors transmit no essentialness of their own. On the other hand, possibly they recognize essentialness from two sources:

- Energy transmitted from automobiles, highway surfaces, and distinctive things in their field-ofpoint of view.

- Energy transmitted from atmosphere and replicated by automobiles, highway surfaces, or distinctive things into the device crevice.

The essentialness got by dynamic infrared sensors is locked in by a photosensitive structure on infrared-sensitive material mounted at the central level of the optics. This material changes over the replicated and released imperativeness into electrical signs. Consistent sign planning is used to separate the signs for the proximity of an automobile. The sensors are fixed above to outlook mov- ing closer or leaving development. Sensors can in like manner be mounted in a side-looking setup. Infrared devices are used for sign control; volume, speed, and class estimation.

\subsubsection{Ultrasonic}

Agarwal et al. (2009) proposed another DAS (Driver Assistance System) taking into account financially savvy ultrasonic sensor for congested movement conditions. This one can possibly be utilized for stopping help framework.

Ultrasonic sensors are utilized to sense deterrents, since they have various favorable circumstances over different sorts of sensors to recognize objects in a short proximity. The impedance is a typical issue when there are numerous ultrasonic sensors are executed.

A straightforward technique taking into account the utilization of microcontrollers to lessen obstruction between the sensors is depicted, which is accomplished by terminating every transducer by a pseudo-arbitrary number of heartbeats for the reverberation of every transducer must be recognized. Today's DAS frameworks require more opportunity to dependably identify objects, which makes them unsatisfactory, where time is basic.

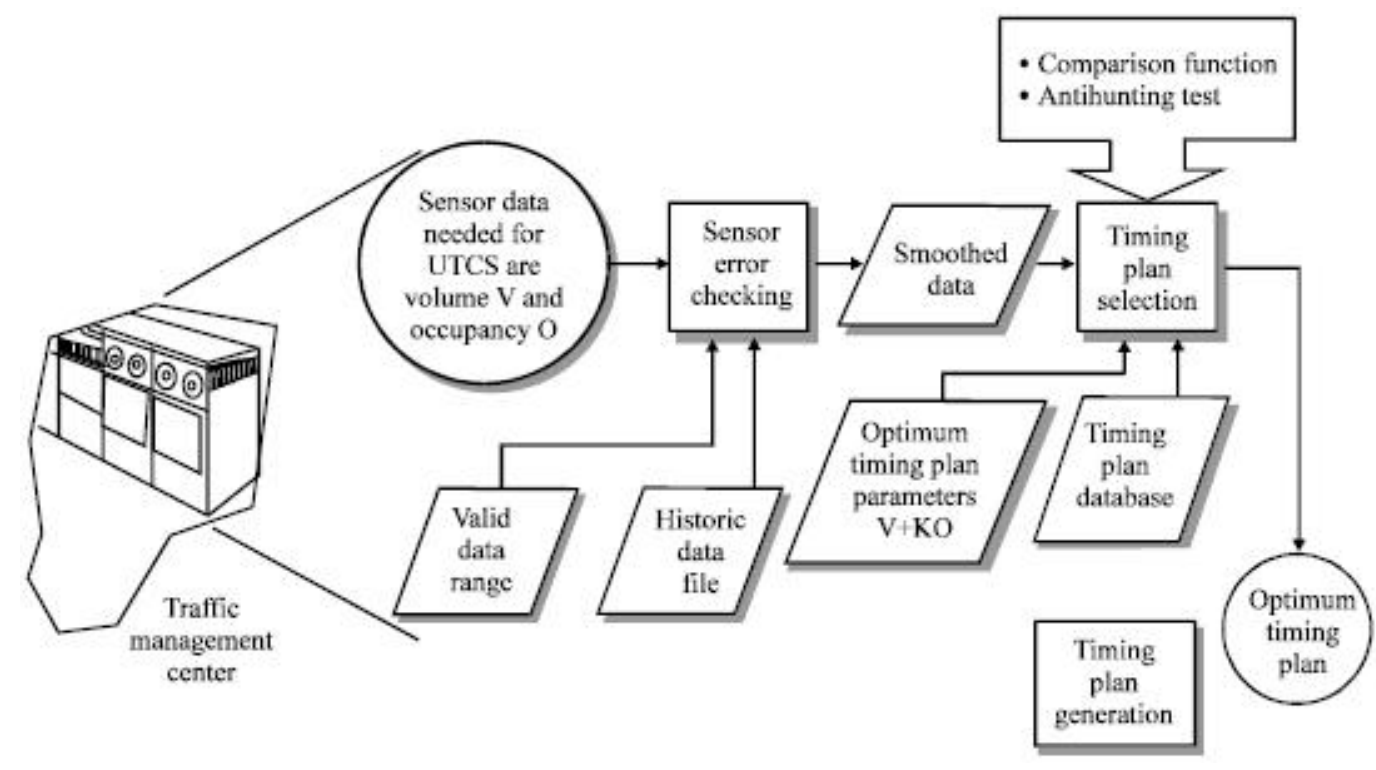

Figure 2. EEG signals before and after the pre-processing steps 
They propose likewise a technique to lessen the time snag location, however once more, the strength of continuous is not justified. The expense of this elite framework is sensible. Continuously when a separation other than on the surface of the street asset is dignified, the instrument translates that estimation as the nearness of an automobile. The ultrasound vitality got is changed over into electrical vitality, which goes alongside the sign preparing. Timing arrangements are appeared in Figure 7.

\subsubsection{Video Image Processing}

Video cameras were familiar with development organization for roadway perception checking their facility to convey close circuit TV pictures to a mortal director for explanation. A Video Picture Processor (VIP) structure routinely contains one or additional cameras, a microchip centered PC for digitizing and exploring the pictures, and programming for interpreting the photos and changing over them into action stream records. VIP can supplant a couple in-ground inductive circles, give ID of automobiles over a couple of ways, and possibly cut down bolster charges' VIPs can hatch automobiles according to their length (commonly three length request degrees are open) and report automobile proximity, volume, way inhabit- ance, and rate for respectively class and way. VIPs that track automobiles might similarly be able to enroll turning improvements and way changes. Vehicle thickness, join travel time, and source target sets are possible action constraints that can be procured by separating records from a movement of picture processors presented sideways a fragment of highway. The sorts of info gave by VIPs makes proper to vein and turnpike applications.

VIP systems recognize automobiles through the examination of high complexity or shading pictures amassed by cameras at a territory of highway. High difference picture examination is executed by counts that break down the assortment of faint levels in social events of pixels confined in the video plots.Summary

There are various sensor technologies already exists for traffic data collection. Every technique has its strength and weakness depending on various measures. The strength and weakness of various measures have been given in Table $1^{\underline{7}}$ This table noticeably tells the various structures of macro level measurement indices.

Further, there are various traffic surveillance techniques which include their own specific applications. The comparison between these surveillances techniques is shown in Table 2.

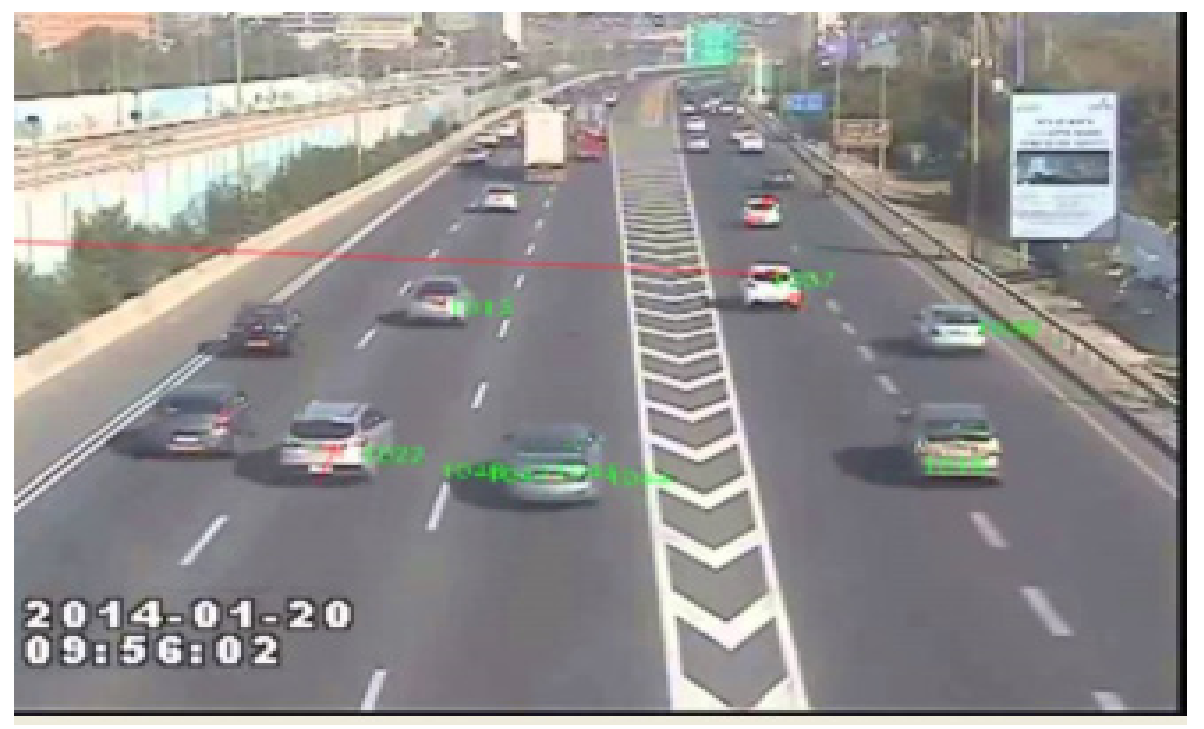

Figure 8. Video image processing ${ }^{11}$. 
Table 1. Advantages and disadvantages of various measures of traffic measurement

\begin{tabular}{|c|c|c|}
\hline Macro Level Indices & Strength & Weakness \\
\hline Travel time and delay & $\begin{array}{l}\text { Time-based blockage } \\
\text { events help in recognizing } \\
\text { significant issues by } \\
\text { empowering strategy } \\
\text { producers to comprehend } \\
\text { issues inside the state } \\
\text { in better path and with } \\
\text { arrangements having most } \\
\text { prominent effect. } \\
\text { Travel time list has the upside } \\
\text { of communicating movement } \\
\text { blockage as far as both space } \\
\text { and time. } \\
\text { The main concepts of } \\
\text { this index are easily } \\
\text { understandable. }\end{array}$ & $\begin{array}{l}\text { Travel time list requires } \\
\text { partition of repeating and } \\
\text { non-repeating delay. It can be } \\
\text { hard to quantify non-repeating } \\
\text { information. } \\
\text { Travel time measures are not } \\
\text { receptive to irregular conditions } \\
\text { Like climatic occasions, } \\
\text { mischances or Development } \\
\text { movement impedances. } \\
\text { Total deferral could likewise } \\
\text { permit transportation experts to } \\
\text { gauge how enhancements inside } \\
\text { a transportation framework } \\
\text { influence a specific passageway or } \\
\text { the whole framework. } \\
\text { The proportion measures are } \\
\text { material just for a specific street } \\
\text { sort or office. We can't utilize } \\
\text { adequately for a geographic area }\end{array}$ \\
\hline Volume and LOS & $\begin{array}{l}\text { Many non-technical people } \\
\text { are able to understand LOS } \\
\text { measure easily. } \\
\text { This is a standard variable in } \\
\text { traffic stream examination. } \\
\text { It is generally utilized in } \\
\text { light of the fact that we can } \\
\text { without much of a stretch } \\
\text { gather this information in the } \\
\text { field. }\end{array}$ & $\begin{array}{l}\text { LOS can't give a consistent scope } \\
\text { of estimations of congestion and } \\
\text { these strategies can't separate } \\
\text { between various levels of clog if } \\
\text { once congestion circumstances are } \\
\text { emerging. } \\
\text { Lane-Mile Duration Index } \\
\text { can't demonstrate the impact } \\
\text { of having diverse expressway } \\
\text { capacities on traffic congestion. }\end{array}$ \\
\hline
\end{tabular}


Table 1 Continued

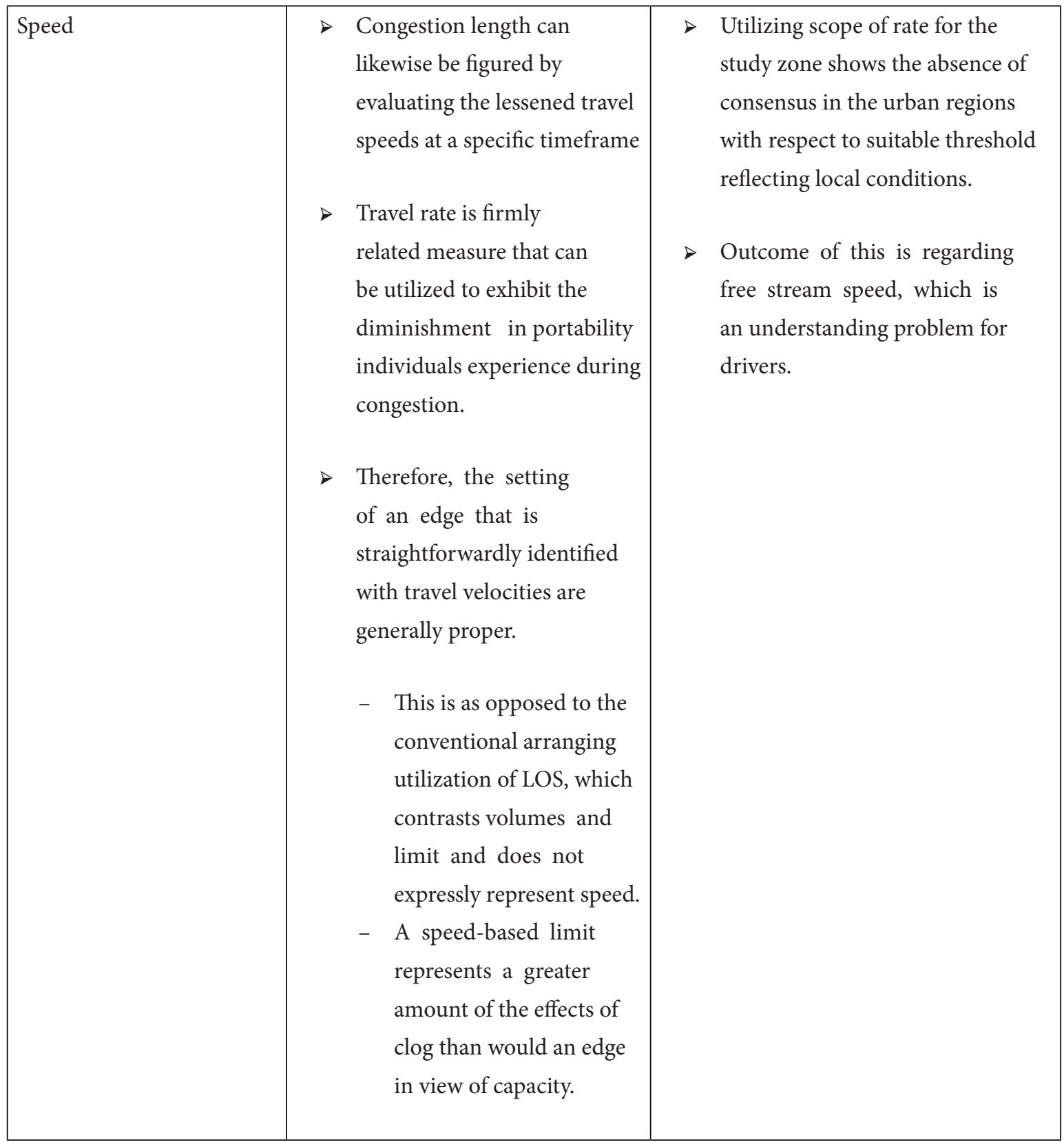


Table 2. Traffic surveillance techniques comparison depending on various parameters

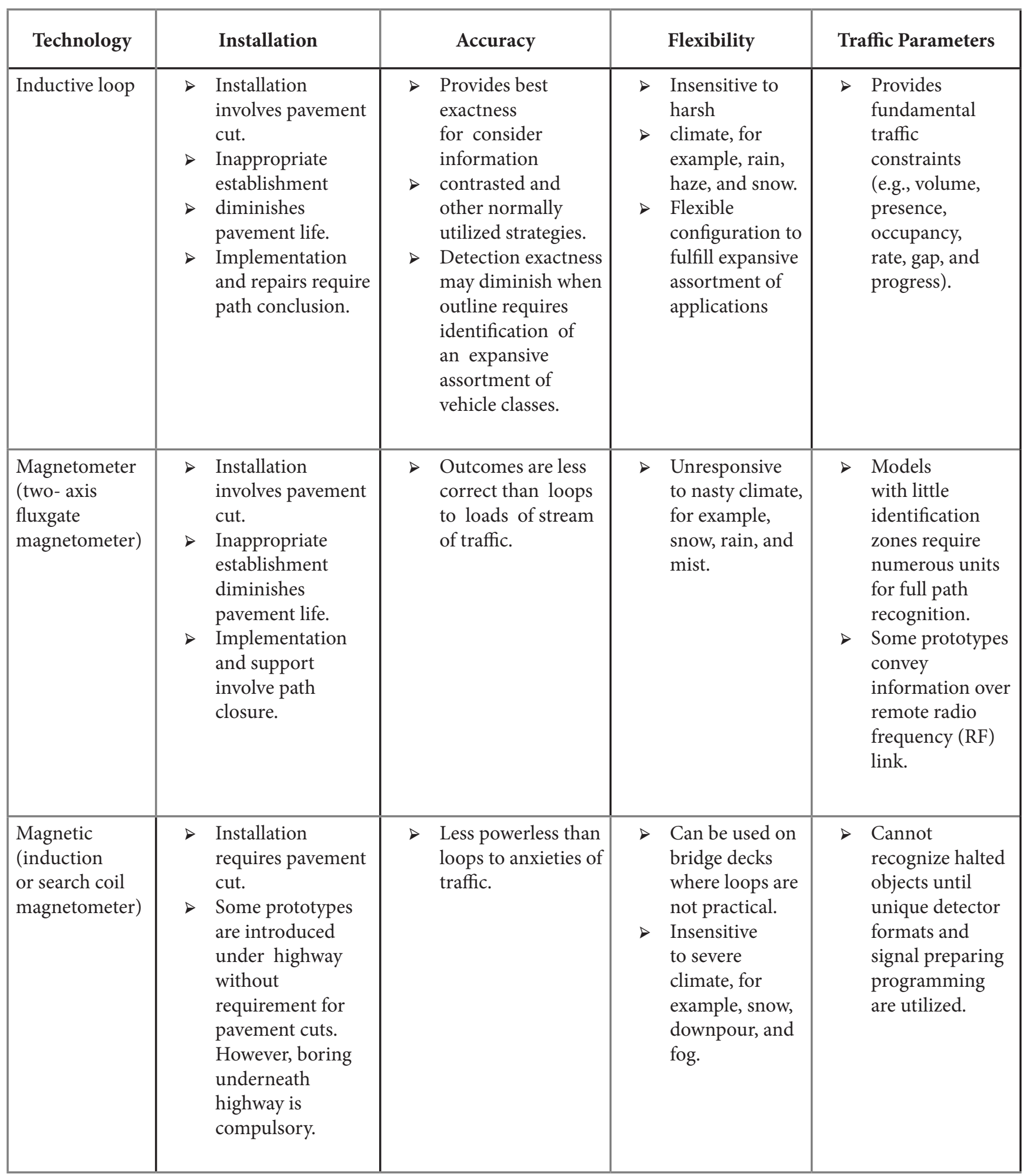


Table 2 Continued

\begin{tabular}{|c|c|c|c|c|c|c|c|c|}
\hline $\begin{array}{l}\text { Microwave } \\
\text { radar }\end{array}$ & & $\begin{array}{l}\text { Microwave radar } \\
\text { can be fixed on } \\
\text { directly above } \\
\text { augmentations, } \\
\text { posts or shaft arms } \\
\text { transmit indicators } \\
\text { that are replicated } \\
\text { off automobiles } \\
\text { back to the } \\
\text { detector. }\end{array}$ & $D$ & $\begin{array}{l}\text { Radar fixed in } \\
\text { the orward- } \\
\text { looking course. } \\
\text { Side-mounted, } \\
\text { particular } \\
\text { acknowledgment } \\
\text { region radars are } \\
\text { to a great degree } \\
\text { exact. } \\
\text { Radar utilized as a } \\
\text { part of multilane } \\
\text { traffic recognition } \\
\text { is less accurate. }\end{array}$ & $\Delta$ & $\begin{array}{l}\text { Typically, } \\
\text { obtuse to severe } \\
\text { climate at the } \\
\text { moderately } \\
\text { short ranges } \\
\text { experienced } \\
\text { in activity } \\
\text { administration } \\
\text { applications. } \\
\text { Multiple path } \\
\text { operation } \\
\text { available. }\end{array}$ & $D$ & $\begin{array}{l}\text { Direct } \\
\text { estimation of } \\
\text { speed. } \\
\text { Continuous } \\
\text { wave (CW) } \\
\text { Doppler sensors } \\
\text { can't identify } \\
\text { halted vehicles }\end{array}$ \\
\hline $\begin{array}{l}\text { Active infrared } \\
\text { (laser radar) }\end{array}$ & $\triangleright$ & $\begin{array}{l}\text { Installation and } \\
\text { support, including } \\
\text { intermittent focal } \\
\text { point cleaning, } \\
\text { require path } \\
\text { closure. }\end{array}$ & $\triangleright$ & Provide exact data. & 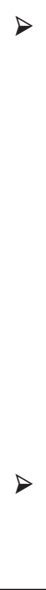 & $\begin{array}{l}\text { Operation } \\
\text { might be } \\
\text { influenced By } \\
\text { mist at the } \\
\text { point when } \\
\text { visibility is less } \\
\text { than } 20 \text { feet } \\
\text { (ft.) } 6 \mathrm{~m} \text { ) or } \\
\text { blowing snow } \\
\text { is accessible } \\
\text { information. } \\
\text { Multiple way } \\
\text { operation } \\
\text { accessible. }\end{array}$ & $\triangleright$ & $\begin{array}{l}\text { Transmits } \\
\text { various bars } \\
\text { for exact } \\
\text { estimation of } \\
\text { vehicle location, } \\
\text { speed, and class. } \\
\text { Establishment } \\
\text { and upkeep, } \\
\text { including } \\
\text { occasional focal } \\
\text { point cleaning, } \\
\text { require path } \\
\text { conclusion. }\end{array}$ \\
\hline Passive infrared & $\triangleright$ & $\begin{array}{l}\text { Installation and } \\
\text { support, including } \\
\text { occasional focal } \\
\text { point cleaning, } \\
\text { require path } \\
\text { closure. }\end{array}$ & 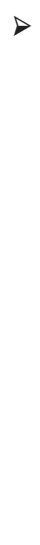 & $\begin{array}{l}\text { Provide precise } \\
\text { data. }\end{array}$ & $D$ & $\begin{array}{l}\text { Passive radar } \\
\text { mayhave } \\
\text { lessened } \\
\text { automobile } \\
\text { affectability } \\
\text { in substantial } \\
\text { thick rain, snow } \\
\text { and thick haze. } \\
\text { Several } \\
\text { prototypes } \\
\text { not Suggested } \\
\text { for nearness } \\
\text { recognition. }\end{array}$ & $\triangleright$ & $\begin{array}{l}\text { Multilane } \\
\text { passive sensors } \\
\text { measure speed. }\end{array}$ \\
\hline
\end{tabular}


Table 2 Continued

\begin{tabular}{|c|c|c|c|c|c|c|c|}
\hline $\begin{array}{l}\text { Video image } \\
\text { processor }\end{array}$ & $\begin{array}{l}\text { Installation and } \\
\text { support, including } \\
\text { intermittent focal } \\
\text { point cleaning, } \\
\text { require path } \\
\text { conclusion when } \\
\text { amera is mounted } \\
\text { above highway. }\end{array}$ & & $\begin{array}{l}\text { Rich range of } \\
\text { information } \\
\text { accessible. } \\
\text { Be responsible } \\
\text { for wide-territory } \\
\text { identification when } \\
\text { data assembled at } \\
\text { one camera area } \\
\text { can be connected } \\
\text { to another. }\end{array}$ & & $\begin{array}{l}\text { Monitors } \\
\text { various lanes } \\
\text { and different } \\
\text { discovery lane. } \\
\text { Easy to include } \\
\text { and adjust } \\
\text { location zones. } \\
\text { Performance } \\
\text { influenced by } \\
\text { harsh climate, } \\
\text { for example, } \\
\text { mist, rain, and } \\
\text { snow; vehicle } \\
\text { shadows; }\end{array}$ & & $\begin{array}{l}\text { Necessitates } 30 \text { - } \\
\text { to } 50 \text {-ft camera } \\
\text { mounting } \\
\text { stature for } \\
\text { ideal nearness } \\
\text { identification } \\
\text { and rate } \\
\text { estimation. } \\
\text { Reliable evening } \\
\text { signal incitation } \\
\text { requires street } \\
\text { lighting. }\end{array}$ \\
\hline
\end{tabular}

\section{Future Scope and Conclusion}

In this study, we discussed about various kinds of traffic congestion conditions and reasons. Clog exists because of diminishment in speeds, that is the quick explanation behind loss of time and prompts extended vehicle working costs, fuel use, and releases of air pollutions and Green House Gasses (GHGs). Along these lines, the situation of an edge which is direct interrelated to transportable paces is generally proper. Various traffic congestion management measures also introduced to solve or prevent congestion problem. A series of novel techniques for traffic detection and surveillance were also discussed. Almost all the existing surveillance approaches were covered with their strength and weakness. One important aspect to consider in future works is timing. Today still a limitation as well as algorithms to process the data. However, developments in this field will go further in parallel with the new smart cars, so we can be sure of its evolution. Moreover, the research in this area points clearly to the Intelligent Transportation System (ITS). Such systems will improve the current state of transportation by increasing computing and processing capability, communication protocols and power of detection.

\section{References}

1. Jagannathan R(Leidos), Hesham Rakha (VTTI), Joe Bared (FHWA), Neil Spiller (FHWA) VASITE 2014 Annual Meeting - VA Beach. June 26, 2014.

2. Yamamoto S, Hieida Y, Tadaki S.. Effects of bottlenecks on vehicle traffic. Journal of the Physical Society of Japan. 2006; 75(11). 114601. DOI:10.1143/jpsj.75.114601.

3. Geography of TransportSystems. 2016 July 04. Available from: . https://people.hofstra.edu/geotrans/eng/methods/ bottlenecks.html.

4. Mohamad KH. A Framework For Intelligent Decision Support System For Traffic Congestion Management System. Engineering 2010; 02: 270-89..

5. Managing urban traffic congestion. European conference of ministers of transport, OCSE, OECD and ECMT. . Paris, France: OECD Publication; 2007.

6. Evaluation Of Traffic Congestion Relieving Options With Using Cost-Benefit Analysis. 1st ed. University of Hong Kong, Pokfulam Road, Hong Kong. 2005.

7. Rao AM. Rao KR..Measuring Urban Traffic Congestion: A Review. International Journal for Traffic and Transport Engineering. 2(4): 286-305. DOI:10.7708/ijtte.2012.2(4).01

8. Klein LA, Mills MK, Gibson DRP. Traffic detector handbook. 3rd ed. Georgetown Pike McLean, VA: FHWAHRT-06-108;2006. 
9. Mathew T, Ravishankar K. Automated traffic measurement for mixed vehicle-types. Transportation Letters. 3(2):10922. DOI:10.3328/tl.2011.03.02.109-122

10. Lomax STT, Turner S, Shunk G, Levinson HS, Pratt RH, Bay PN, Douglas GB. Quantifying congestion. Volume 1, NCHRP Final Report 398. Washington, D.C: TransportationResearch Board. p.108.

11. Real Time Traffic Counting Systemusing Video Image Processing. 2016 July 17. Available from: https://coeut.iitm. ac.in/umcsp/pdfweb/1a2Subhashis\%20Chaudhuri_IITB. pdf

12. Cheung SY, Coleri S, Dundar B, Tan C, Varaiya P - Traffic Measurement and Vehicle Classification with a Single Magnetic Sensor. Journal of the Transportation Research Board. 2004; 1917

13. Christidis P, Juan Nicolás Ibáñez Rivas. Measuring road congestion. 2012. Available from: http://ftp.jrc.es/EURdoc/ JRC69961.pdf

14. Intermodal $\mathrm{T}$,Transportation $\mathrm{S}$. Measuring Traffic Congestion. Journal of the Transportation Research Board. 1994; 98:93-9.
15. Jain V, Sharma A, Subramanian L. Road traffic congestion in the developing world. Proceedings of the 2nd ACM Symposium on Computing for Development - ACM DEV '12, Atlanta, Georgia. 2012. DOI:10.1145/2160601.2160616

16. Congestion Identification and Bottleneck Prediction. 2016 July 15. Available from: http://vasite.org/images/ downloads/2014_Annual_Meeting_Presentations/2014_ congestion_identification_and_bottleneck_prediction.pdf

17. Byrne GE, Mulhall SM. Congestion management data requirement and comparisons, Transportation Research Record. Journal of the Transportation Research Board 1995; 1499:28-36.

18. Measuring Traffic Congestion- A Critical Review. 30th Australasian Transport Research Forum, Melobourne, Victoria, Australia. 2004.p. 1-16.

19. Cottrell WD. Measurement of the extent and duration of traffic congestion in urban areas. Proceedings of the 61st Annual Meeting, Institute of Transportation Engineers. 1991. 427-32. 